\title{
NÍVEIS CRÍTICOS DE BORO NO SOLO E NA PLANTA PARA CULTIVO DE MUDAS DE MARACUJAZEIRO-AMARELO ${ }^{1}$
}

\author{
RENATO DE MELLO PRADO ${ }^{2,5}$, WILLIAM NATALE ${ }^{3,5}$, DANILO EDUARDO ROZANE ${ }^{4,6}$
}

\begin{abstract}
RESUMO - Objetivou-se avaliar a aplicação de boro ao substrato de produção de mudas de maracujazeiro-amarelo, para o estabelecimento dos níveis críticos do B no solo e na planta. O delineamento experimental foi em blocos ao acaso, com cinco tratamentos e quatro repetições. As doses de boro, na forma de ácido bórico, foram: 0; 0,25; 0,50; 0,75 e 1,0 mg de B dm de solo. As mudas receberam doses de N, P, K e Zn, de 300; $450 ; 150$ e $5 \mathrm{mg} \mathrm{dm}^{-3}$, respectivamente, sendo o $\mathrm{N}$ e o $\mathrm{K}$ parcelados em três vezes (15; 30 e 45 dias após o plantio). O experimento foi conduzido em condições de casa de vegetação, em vasos com $2 \mathrm{dm}^{-3}$ de substrato de um Latossolo Vermelho distrófico. Após 70 dias do plantio, foram avaliados: o diâmetro do caule, a altura da planta, o número de folhas e a matéria seca da parte aérea e das raízes, bem como os teores de macro e micronutrientes. As mudas de maracujazeiro responderam à aplicação de boro em substrato com baixa concentração $\left(0,06 \mathrm{mg} \mathrm{dm}^{-3}\right)$, extraído com água quente. $\mathrm{O}$ maior desenvolvimento das plantas esteve associado à dose próxima de $0,5 \mathrm{mg} \mathrm{de} \mathrm{B} \mathrm{dm}^{-3} \mathrm{e}$ à concentração de $0,4 \mathrm{mg}$ de $\mathrm{B}$ $\mathrm{dm}^{-3}$ no substrato e um teor de $22 \mathrm{mg}$ de $\mathrm{B} \mathrm{kg}^{-1}$ na parte aérea.
\end{abstract}

Termos de indexação: adubação, Passiflora edulis f. flavicarpa, macronutriente, micronutriente, nutrição.

\section{BORON APPLICATION THE NUTRICIONAL STATUS AND DRY MATTER PRODUCTION OF PASSION FRUIT CUTTINGS}

\begin{abstract}
It was objectified to evaluate the application of boron to the substratum of production of yellow passion fruit cuttings, for the establishment of the critical levels of the B in the soil and the plant. The experimental design used was randomized blocks with 5 treatments and 4 replications. The doses of boron were: $0 ; 0,25 ; 0,50 ; 0,75$ and $1,00 \mathrm{mg} \mathrm{dm}^{-3}$ of B. All the plants received doses of N, P, K and Zn of 300; $100 ; 150$ and 5,0 mg dm $\mathrm{m}^{-3}$, respectively. The experiment was lead in vases with $2.0 \mathrm{dm}^{3}$ of substratum of a Typic Haplorthox. After 70 days of the sowing were evaluated: height, leave numeric, dry matter, nutritional status of plants and soil nutrients. The passion fruit plant seedlings answered to the boron application in soil with low concentration of $0,06 \mathrm{mg} \mathrm{dm}-3$ of $\mathrm{B}$, extracted with hot water. The highest development of the plants was associated with the level of B $0,5 \mathrm{mg} \mathrm{dm}^{-3}$ and the content of $0,4 \mathrm{mg} \mathrm{dm}^{-3}$ of B in soil end content of $22 \mathrm{mg}$ of $\mathrm{B} \mathrm{kg} \mathrm{kg}^{-1}$ in the aerial part.

Index terms: Passiflora edulis, macronutrients, manuring, micronutrients, nutrition.
\end{abstract}

\section{INTRODUÇÃO}

Na implantação de um pomar, a qualidade das mudas é fundamental para garantir a homogeneidade, a rápida formação e o início precoce da produção. Considera-se que $60 \%$ do sucesso de uma cultura perene, como as frutíferas, está em implantá-la com mudas de alta qualidade (Minami et al., 1994). Para se obterem mudas de boa qualidade, o estado nutricional da planta é de extrema importância. Entretanto, poucos são os estudos sobre nutrição mineral em frutíferas tropicais, especialmente quanto aos micronutrientes.

Dentre os micronutrientes que mais problemas de deficiência têm causado em culturas brasileiras, incluem-se o boro e o zinco. Como a quantidade destes micronutrientes aplicadas por muda é muito pequena, tem-se alta relação benefício/custo nos sistemas de produção de mudas. Em solos da região do cerrado, a escassez de água, o pH baixo e os altos teores de ferro e de alumínio são fatores que predispõem os solos à deficiência de boro (Magalhães \& Monnerat, 1978); além disso, a matéria orgânica constitui a principal fonte de boro nestes solos e, considerando os baixos teores normalmente presentes, aumentam as chances de ocorrerem deficiências (Buzetti et al., $1990 \mathrm{a}, \mathrm{b})$.

As respostas resultantes da deficiência de boro, em diversas plantas, incluem inibição do crescimento radicular, ausência ou anormalidade na diferenciação vascular, principalmente em relação ao floema, e necrose do ápice radicular (Gupta, 1993b; Marschner, 1995). Com o colapso dos vasos condutores, tem-se a redução do crescimento das raízes que não recebem quantidade suficiente de fotossintatos, e, finalmente, a absorção de água e de nutrientes também é afetada; portanto, o crescimento da planta é diminuído, conforme constatado por Morales Abanto \& Muller (1977) com maracujazeiro.

Salienta-se, ainda, que o manejo adequado do boro no sistema solo-planta é normalmente dificultado, pois a faixa de concentração entre a deficiência e a toxicidade é a menor, se comparada à dos outros nutrientes. Soma-se a isto o fato de que o aumento da concentração de B nas plantas pode diminuir a concentração de outros nutrientes, como de P, Ca e Fe (Sotiropoulos et al.,1999), e não alterar outros, como K e Mg (Yamagishi \& Yamamoto, 1994), sendo que a interação mais estudada é do B com o Ca (Ramon et al., 1990).

São necessárias mais pesquisas para uma recomendação mais precisa da adubação boratada para as culturas em geral (Yamada, 2000), e especificamente para mudas de maracujazeiro, pois as pesquisas não são ainda suficientes para a indicação de adubação em substrato à base de solo. Na literatura, os resultados da resposta do maracujazeiro ao boro indicam efeito positivo (crescimento radicular), em experimentação com solução nutritiva (Grassi Filho et al., 2000) e em solo. Entretanto, o B foi aplicado junto com o Zn, Cu e Mo (Oliveira Jr. et al., 1994), o que dificulta uma adequada interpretação do papel de cada micronutriente na planta. Outros resultados não apresentam efeito significativo na produção de matéria, com a aplicação deste nutriente na forma de ácido bórico via foliar, em mudas de maracujazeiro-amarelo (Peixoto \& Carvalho, 1996).

Diante deste contexto, objetivou-se avaliar a aplicação de boro ao substrato de produção de mudas de maracujazeiro-amarelo, para o estabelecimento dos níveis críticos do B no substrato e na planta.

\footnotetext{
1 (Trabalho 209-2005). Recebido: 19-12-2005. Aceito para publicação: 07-06-2006.

${ }^{2}$ Professor Doutor, Depto. de Solos e Adubos, Universidade Estadual Paulista, Fac. de Ciências Agrárias e Veterinárias. Via de Acesso Prof. Paulo Donato Castellane, s/n. 14870-000, Jaboticabal-SP. E-mail: rmprado@ fcav.unesp.br.

${ }^{3}$ Professor Adjunto, Depto. de Solos e Adubos, Universidade Estadual Paulista, Fac. de Ciências Agrárias e Veterinárias. E-mail: natale @fcav.unesp.br.

${ }^{4}$ Engenheiro Agrônomo, Mestrando, Depto. Solos e Adubos, Universidade Estadual Paulista, Fac. de Ciências Agrárias e Veterinárias. E-mail: danilorozane@yahoo.com.br

${ }^{5}$ Bolsista do CNPq.

${ }^{6}$ Bolsista da FAPESP.
} 


\section{MATERIAL E MÉTODOS}

O presente trabalho foi conduzido em condições de casa de vegetação, na FCAV/Unesp, Câmpus de Jaboticabal-SP. Como substrato, utilizou-se o subsolo de um Latossolo Vermelho distrófico (camada 3-4 m de profundidade), do qual amostras foram submetidas a análises químicas antes da calagem e após 30 dias de incubação, por ocasião do plantio. Cerca de 30 dias antes da semeadura do maracujazeiro-amarelo (Passiflora edulis f. flavicarpa Deneger), realizou-se a aplicação de corretivo de acidez com o objetivo de elevar o V a 80\%, conforme recomendação de Piza Júnior et al. (1996). Para isto, utilizou-se o calcário calcinado, com as seguintes características: $\mathrm{CaO}=420 \mathrm{~g} \mathrm{~kg}^{-1} ; \mathrm{MgO}=250 \mathrm{~g} \mathrm{~kg}^{-1} ; \mathrm{PN}=137 \% ; \mathrm{RE}=96 \%$ e PRNT $=$ $131 \%$. A dose de calcário calculada $\left(0,9 \mathrm{t} \mathrm{ha}^{-1}\right.$ ou $0,880 \mathrm{~g}$ por vaso de 2 $\mathrm{dm}^{3}$ ) foi homogeneamente aplicada ao substrato, a fim de que o corretivo tivesse tempo suficiente para neutralizar a acidez do substrato. Durante o período de incubação, o substrato foi mantido úmido (70\% da capacidade de campo).

Assim, os principais atributos químicos apresentaram os seguintes resultados, para antes e após a incubação, respectivamente: $\mathrm{pH}=4,4$ e 5,$7 ; \mathrm{M} . \mathrm{O} .=7$ e $6 \mathrm{~g} \mathrm{dm}^{-3} ; \mathrm{P}$ (resina) $=2$ e $2 \mathrm{mg} \mathrm{dm}^{-3} ; \mathrm{K}=0,5$ e 0,8 ; $\mathrm{Ca}=4$ e $27 ; \mathrm{Mg}=2$ e $10 ;(\mathrm{H}+\mathrm{Al})=16$ e $12 ; \mathrm{SB}=6,5$ e 37,$8 ; \mathrm{CTC}=22,5$ e $49,8 \mathrm{mmol} \mathrm{dm}^{-3} ; \mathrm{V}=29$ e $76 \% ; \mathrm{B}=0,09$ e $0,06 \mathrm{mg} \mathrm{dm}^{-3}$. A análise granulométrica apresenta os seguintes resultados: $210 \mathrm{~g} \mathrm{~kg}^{-1} \mathrm{de}$ argila; $40 \mathrm{~g} \mathrm{~kg}^{-1}$ de silte; $440 \mathrm{~g} \mathrm{~kg}^{-1}$ de areia fina, e $310 \mathrm{~g} \mathrm{~kg}^{-1}$ de areia grossa.

O delineamento experimental adotado foi em blocos casualizados, com cinco tratamentos e quatro repetições. Os tratamentos foram doses crescentes de boro, na forma de ácido bórico (17 $\left.\mathrm{g} \mathrm{kg}^{-1} \mathrm{de} \mathrm{B}\right)$, considerando-se como padrão a dose de $0,5 \mathrm{mg} \mathrm{dm}^{-3}$ de $\mathrm{B}$, indicada como adequada para experimentos em condições de vasos, segundo a recomendação geral de Malavolta (1981). As doses aplicadas foram: $\mathrm{D}_{0}=$ zero de $\mathrm{B} ; \mathrm{D}_{1}=0,25 ; \mathrm{D}_{2}=0,5 ; \mathrm{D}_{3}=0,75 ; \mathrm{D}_{4}=1,0$ $\mathrm{mg}$ de $\mathrm{B} \mathrm{dm} \mathrm{de}^{-3}$ de substrato. $\mathrm{O}$ substrato de cada vaso, com capacidade de $2 \mathrm{~L}$, recebeu ainda: $450 \mathrm{mg} \mathrm{dm}^{-3}$ de $\mathrm{P}$, conforme indicação de Machado (1998); $300 \mathrm{mg} \mathrm{dm}^{-3} \mathrm{de} \mathrm{N} ; 150 \mathrm{mg} \mathrm{dm}^{-3} \mathrm{de} \mathrm{K}$, e $5 \mathrm{mg} \mathrm{dm}^{-3} \mathrm{de}$ Zn de acordo com a recomendação geral de Malavolta (1981), na forma de superfosfato triplo ( $440 \mathrm{~g} \mathrm{~kg}^{-1} \mathrm{de}_{2} \mathrm{O}_{5}$ ), sulfato de amônio (200 $\left.\mathrm{g} \mathrm{kg}^{-1} \mathrm{de} \mathrm{N}\right)$, cloreto de potássio $\left(600 \mathrm{~g} \mathrm{~kg}^{-1} \mathrm{de} \mathrm{K}_{2} \mathrm{O}\right)$ e sulfato de zinco $\left(220 \mathrm{~g} \mathrm{~kg}^{-1} \mathrm{de} \mathrm{Zn}\right)$. O N e o K foram parcelados em três aplicações, aos $15 ; 30$ e 45 dias após a semeadura. O P e o $\mathrm{Zn}$ foram adicionados na dose total na semeadura, juntamente com os tratamentos com B.

Empregaram-se cinco sementes do maracujazeiro-amarelo por vaso (05-04-2003). Uma semana após a emergência das plântulas, realizou-se o desbaste, deixando-se duas plantas por vaso até o final do experimento.

A irrigação foi realizada para manter a umidade em teor correspondente a $70 \%$ da capacidade de campo.

Aos 70 dias após a semeadura, foram avaliadas as variáveis biológicas indicativas do crescimento das plantas: altura, diâmetro do caule, número de folhas, matéria seca da parte aérea e das raízes das plantas. Na mesma ocasião, o estado nutricional das plantas foi avaliado, dividindo-se as mudas em parte aérea e raízes. As determinações dos teores de macro e micronutrientes no tecido vegetal seguiram a metodologia de Bataglia et al. (1983). Calculou-se o índice de translocação do B (conteúdo do nutriente na parte aérea/conteúdo de nutriente na planta). Na mesma época do corte das plantas, realizouse amostragem do substrato para avaliação de fertilidade. Amostras do substrato foram analisadas para determinação de pH, M.O.; P; K; $\mathrm{Ca} ; \mathrm{Mg} ;(\mathrm{H}+\mathrm{Al})$ e B (Raij et al., 2001). Com estes resultados, calcularamse: $\mathrm{SB} ; \mathrm{CTC}$ e V.

Com base nos resultados obtidos, realizaram-se a análise de variância para as diversas variáveis estudadas e a análise de regressão entre as doses de $\mathrm{B}$ e as determinações no substrato e na planta.

\section{RESULTADOS E DISCUSSÃO}

\section{Efeito dos tratamentos no substrato}

A aplicação do calcário ao substrato promoveu a neutralização da acidez, elevando a saturação por bases a $76 \%$. Ressalta-se que, para o Estado de São Paulo, foram definidas as classes de teores de $\mathrm{B}$ (extrator água quente), considerados baixos, entre 0,0 a $0,20 \mathrm{mg} \mathrm{dm}^{-3}$, médios, de 0,21 a $0,60 \mathrm{mg} \mathrm{dm}^{-3}$, e altos, > 0,60 $\mathrm{mg} \mathrm{dm}^{-3}$ (Raij et al., 1996). O substrato do presente experimento apresentou teor de $\mathrm{B}$ de $0,06 \mathrm{mg} \mathrm{dm}^{-3}$, o que está na classe de teor considerado baixo.

A aplicação de B causou aumento da concentração de boro no substrato (Figura 1). A relação entre B aplicado e recuperado pelo extrator foi $64 \%$ (Figura 1 ).

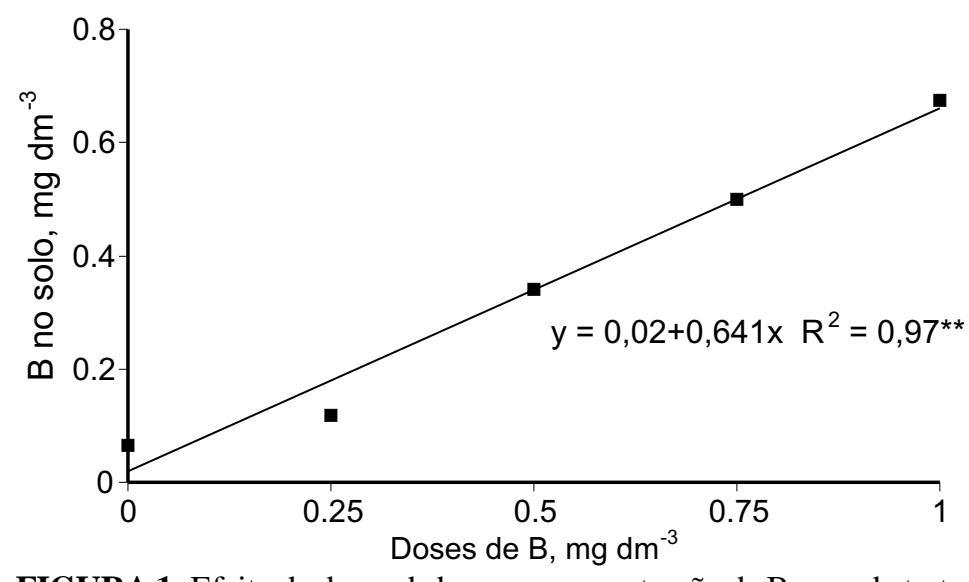

FIGURA 1- Efeito de doses de boro na concentração de B em substrato do Latossolo Vermelho distrófico (extrator água quente).

\section{matéria seca}

Efeito dos tratamentos no desenvolvimento e na produção de

Houve efeito significativo das doses de boro sobre a altura, o diâmetro do caule e o número de folhas das mudas de maracujazeiro, sendo oportuno ressaltar que a altura e o diâmetro do caule apresentam a mesma curva de resposta, sob as doses de B empregadas [Figuras 2 - (a) e (b)]. Pelo estudo das regressões, verificou-se que as plantas atingiram o máximo desenvolvimento com a dose de $0,6 \mathrm{mg} \mathrm{de} \mathrm{B} \mathrm{dm}-$ ${ }^{3}$. Nas maiores doses de boro, as plantas apresentaram decréscimo no desenvolvimento. Entretanto, a sintomatologia de toxidez que, segundo Malavolta et al. (1997), se caracteriza por clorose malhada e depois por manchas necróticas (zonas de acumulação), ocorreu em menor intensidade, apenas na fase inicial de desenvolvimento (até 20 dias), no tratamento com a dose máxima de $\mathrm{B}\left(1 \mathrm{mg} \mathrm{dm}^{-3}\right)$ e, após este período, a sintomatologia diminuiu, desaparecendo após 40 dias da semeadura.

A matéria seca da parte aérea e das raízes das mudas de maracujazeiro foi afetada de forma quadrática pelas doses de boro (Figura 3).

Da mesma forma que ocorreu com as variáveis de desenvolvimento, a maior produção de matéria seca da parte aérea e das raízes esteve associada à dose próxima a $0,5 \mathrm{mg} \mathrm{dm}^{-3} \mathrm{de} \mathrm{B}$ (Figura 3). A partir dessa dose, houve redução na produção de matéria seca. Na dose para a produção máxima, comparada à testemunha, resultou em maior incremento na produção de matéria seca de raízes $(67 \%) \mathrm{em}$ relação à parte aérea (62\%) (Figura 3). Kirk \& Loneragan (1988) também indicaram uma resposta maior ao crescimento de raízes do que da parte aérea das plantas de soja em função da aplicação de boro.

Estes dados discordam, em parte, de Grassi Filho et al. (2000), que avaliaram, em solução nutritiva, doses de $\mathrm{B}\left(0\right.$ até $\left.30 \mathrm{mg} \mathrm{L}^{-1} \mathrm{de} \mathrm{B}\right)$ no desenvolvimento de mudas de maracujazeiro e observaram que as mesmas favoreceram positivamente o crescimento radicular e negativamente o crescimento da parte aérea. 

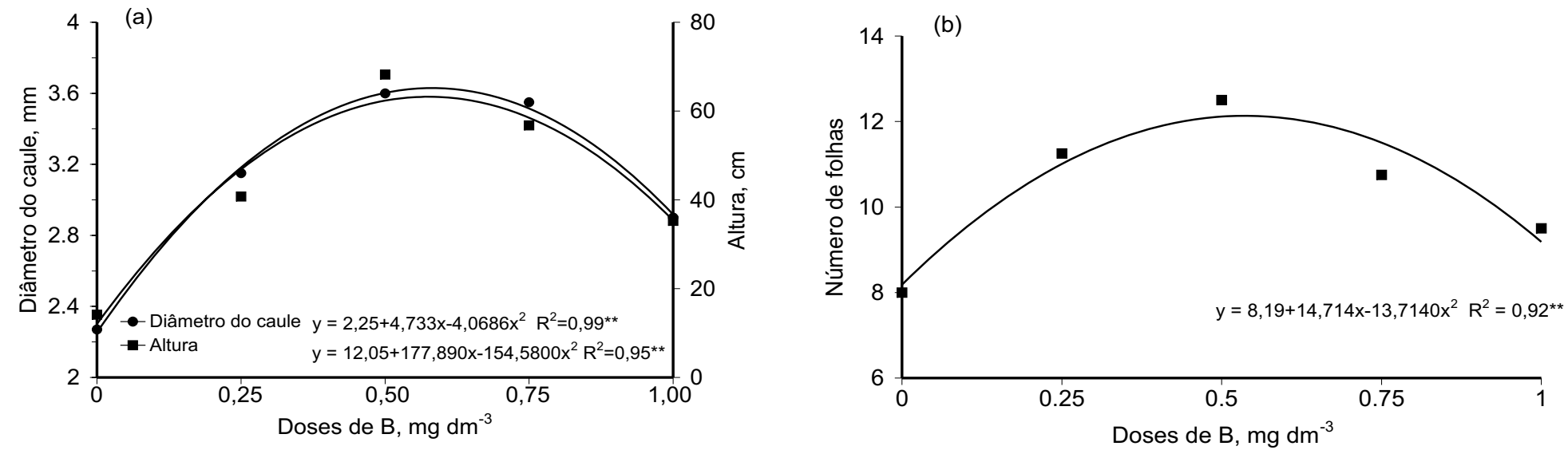

FIGURA 2- Efeito da aplicação de boro em substrato do Latossolo Vermelho distrófico no diâmetro do caule, na altura (a) e no número de folhas (b) das mudas de maracujazeiro-amarelo, aos 70 dias após a semeadura.

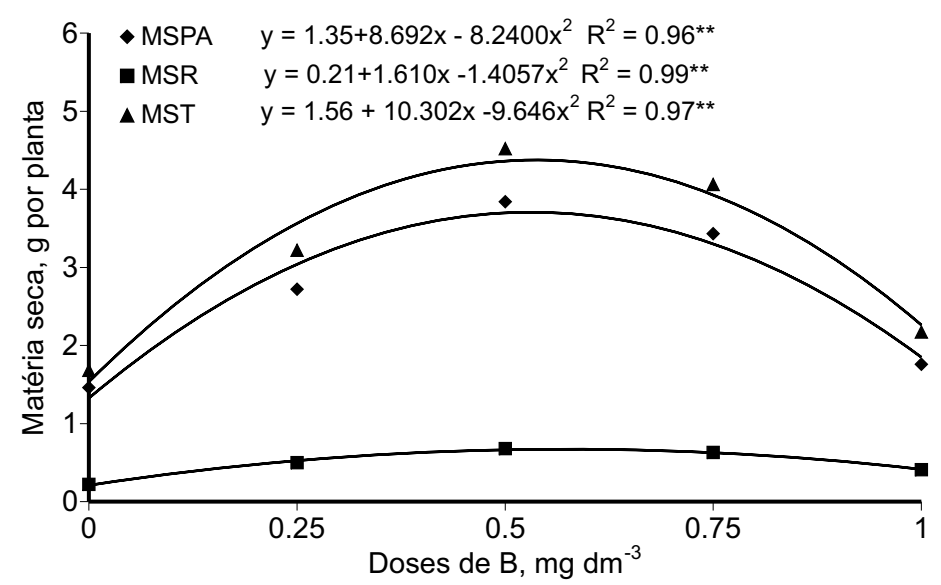

FIGURA 3 - Efeito da aplicação de boro em substrato do Latossolo Vermelho distrófico na produção de matéria seca da parte aérea (MSPA) e matéria seca de raiz (MSR) e matéria seca total (MST) das mudas de maracujazeiro-amarelo, aos 70 dias após a semeadura.

É oportuno destacar que a maior produção de matéria seca da parte aérea e de raízes do maracujazeiro esteve associada à concentração de B no substrato, próxima a $0,4 \mathrm{mg} \mathrm{dm}^{-3}$ (Figura 4). Em outras culturas, como do algodão (Silva et al., 1991) e do girassol (Bataglia \& Raij, 1990), a melhor resposta à adubação com boro situase em solo com 0,2-0,4 $\mathrm{mg} \mathrm{dm}^{-3}$ em e com 0,2-0,5 $\mathrm{mg} \mathrm{dm}^{-3}$, respectivamente, sendo que a concentração de $\mathrm{B}$ maior que $0,5 \mathrm{mg}$ $\mathrm{dm}^{-3}$ causou uma queda expressiva na matéria seca das plantas. Inexiste a indicação do nível de $\mathrm{B}$ no solo, considerado tóxico tanto em mudas como em plantas adultas de maracujazeiro-amarelo.

Os resultados deste trabalho indicam a importância da aplicação de boro e da definição de suas concentrações em programas de adubação de mudas.

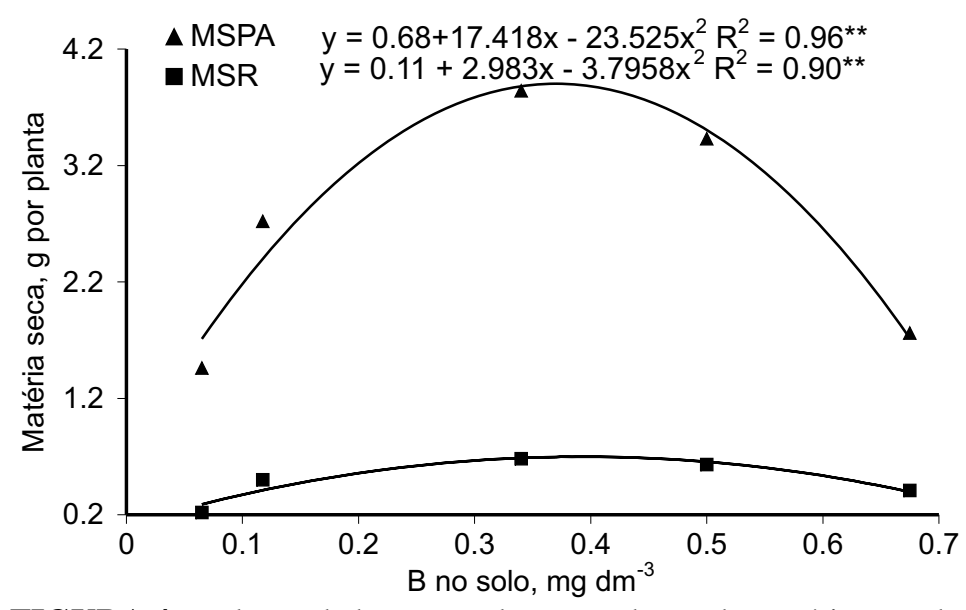

FIGURA 4 - Relação do boro no solo e a produção de matéria seca da parte aérea (MSPA) e da matéria seca de raízes (MSR) de mudas de maracujazeiro-amarelo, 70 dias após a semeadura.

\section{Efeitos dos tratamentos no estado nutricional}

A aplicação de B não alterou significativamente os teores de $\mathrm{N}, \mathrm{K}$ e $\mathrm{S}$ na parte aérea (Tabela 1) e nas raízes de $\mathrm{N}, \mathrm{K}, \mathrm{Mg}$, S e Zn (Tabela 2). Na parte aérea, a aplicação de B diminui os teores de P, Ca, $\mathrm{Mg}, \mathrm{Cu}$ e $\mathrm{Mn}$ com comportamento quadrático, e os de Fe e $\mathrm{Zn}$, de forma linear. Os teores de B aumentaram linearmente. Nas raízes, os teores de $\mathrm{Ca}$ e $\mathrm{Cu}$ diminuíram de forma quadrática, enquanto nos de $\mathrm{P}$ e $\mathrm{Mn}$, a diminuição foi linear. $\mathrm{O}$ de $\mathrm{B}$ aumentou linearmente com a aplicação deste nutriente. É oportuno salientar que a aplicação do B, por promover o incremento de matéria seca, pode provocar diluição dos nutrientes absorvidos em relação ao tratamento sem boro.

Resultados semelhantes da interferência do B no teor de outros nutrientes foram também obtidos por outros autores, a exemplo de Gupta (1993a), que relatou a diminuição dos teores de Zn, Fe e Mn

TABELA 1 - Teores de macro e micronutrientes na matéria seca da parte aérea de mudas de maracujazeiro-amarelo, em função de doses de boro, aos 70 dias após a semeadura.

\begin{tabular}{|c|c|c|c|c|c|c|c|c|c|c|c|}
\hline Doses B & $\mathrm{N}$ & $\mathrm{P}$ & $\mathrm{K}$ & $\mathrm{Ca}$ & $\mathrm{Mg}$ & $\mathrm{S}$ & $\mathrm{B}$ & $\mathrm{Cu}$ & $\mathrm{Fe}$ & $\mathrm{Mn}$ & $\mathrm{Zn}$ \\
\hline $\mathrm{mg} \mathrm{dm}^{-3}$ & & & & $\mathrm{~g}^{-1}$ & & & & & $\mathrm{mg} \mathrm{kg}^{-1}$ & & \\
\hline 0,00 & 44,9 & 4,7 & 22,3 & 17,2 & 3,4 & 3,1 & 9 & 3,3 & 111 & 134 & 54 \\
\hline 0,25 & 39,1 & 3,8 & 25,0 & 13,2 & 2,5 & 2,9 & 13 & 3,5 & 82 & 89 & 46 \\
\hline 0,50 & 33,6 & 3,1 & 25,4 & 11,3 & 2,4 & 2,7 & 21 & 3,3 & 73 & 79 & 43 \\
\hline 0,75 & 36,1 & 3,5 & 27,9 & 14,0 & 2,3 & 2,8 & 25 & 2,3 & 71 & 76 & 38 \\
\hline 1,00 & 42,7 & 3,3 & 26,1 & 13,1 & 2,3 & 2,9 & 33 & 1,5 & 70 & 75 & 34 \\
\hline Teste F & $1,6^{\mathrm{nS}}$ & $9,8^{* * *}$ & $1,6^{\mathrm{ns}}$ & $4,7^{*}$ & $8,1^{*}$ & $2,3^{\mathrm{ns}}$ & $88,4^{* *}$ & $6,0 * *$ & $9,3^{* *}$ & $22,1^{* *}$ & $3,9 * *$ \\
\hline RL & - & - & - & - & - & - & $348,9^{* *}$ & - & $27,0^{\text {** }}$ & - & $15,1 * *$ \\
\hline RQ & - & $11,3^{*}$ & - & $8,4 * *$ & 9,0 * & - & & $19,0^{* *}$ & & $23,2^{* *}$ & - \\
\hline C.V.(\%) & 18,7 & 10,7 & 12,6 & & 12,9 & 7,1 & 10,0 & 25,0 & 13,9 & 11,7 & 18,3 \\
\hline
\end{tabular}

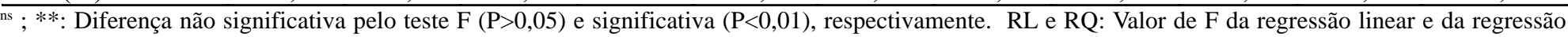
quadrática, respectivamente. 
TABELA 2 - Teores de macro e micronutrientes na matéria seca das raízes de mudas de maracujazeiro-amarelo, em função de doses de boro, aos 70 dias após a semeadura.

\begin{tabular}{|c|c|c|c|c|c|c|c|c|c|c|}
\hline Doses B & $\mathrm{N}$ & $\mathrm{P}$ & $\mathrm{K}$ & $\mathrm{Ca}$ & $\mathrm{Mg}$ & $\mathrm{S}$ & B & $\mathrm{Cu}$ & $\mathrm{Mn}$ & $\mathrm{Zn}$ \\
\hline $\mathrm{mg} \mathrm{dm}^{-3}$ & & \multicolumn{5}{|c|}{$\mathrm{g} \mathrm{kg}^{-1}$} & \multicolumn{4}{|c|}{$\mathrm{mg} \mathrm{kg}^{-1} \Longleftarrow$} \\
\hline 0,00 & 21,2 & 5,0 & 16,3 & 7,1 & 2,9 & 2,2 & 7 & 8 & 195 & 88 \\
\hline 0,25 & 19,2 & 4,3 & 18,0 & 5,4 & 2,5 & 1,9 & 14 & 9 & 159 & 87 \\
\hline 0,50 & 16,5 & 4,0 & 19,3 & 5,5 & 2,5 & 1,7 & 24 & 9 & 142 & 82 \\
\hline 0,75 & 18,0 & 3,9 & 23,8 & 5,3 & 2,3 & 2,3 & 26 & 7 & 138 & 79 \\
\hline 1,00 & 20,5 & 3,7 & 18,5 & 5,9 & 2,2 & 2,1 & 36 & 6 & 131 & 73 \\
\hline Teste F & $1,1^{\mathrm{ns}}$ & $8,2^{* * 2}$ & $2,9^{\mathrm{ns}}$ & $5,2^{*}$ & $1,8^{\mathrm{ns}}$ & $3,1^{\mathrm{ns}}$ & $88,4^{* *}$ & $13,7^{*}$ & $3,9^{*}$ & $2,7^{\text {ns }}$ \\
\hline RL & - & $29,0^{* *}$ & - & - & - & - & $345,8^{* *}$ & - & $13,1^{* *}$ & - \\
\hline RQ & - & - & - & $13,0^{* *}$ & - & - & - & $21,7^{* *}$ & - & - \\
\hline C.V.(\%) & 18,7 & 8,1 & 17,2 & 11,3 & 16,8 & 14,9 & 11,3 & 9,8 & 17,2 & 9,6 \\
\hline
\end{tabular}

ns ; **: Diferença não significativa pelo teste $\mathrm{F}(\mathrm{P}>0,05)$ e significativa $(\mathrm{P}<0,01)$, respectivamente. RL e RQ: Valor de $\mathrm{F}$ da regressão linear e da regressão quadrática, respectivamente.
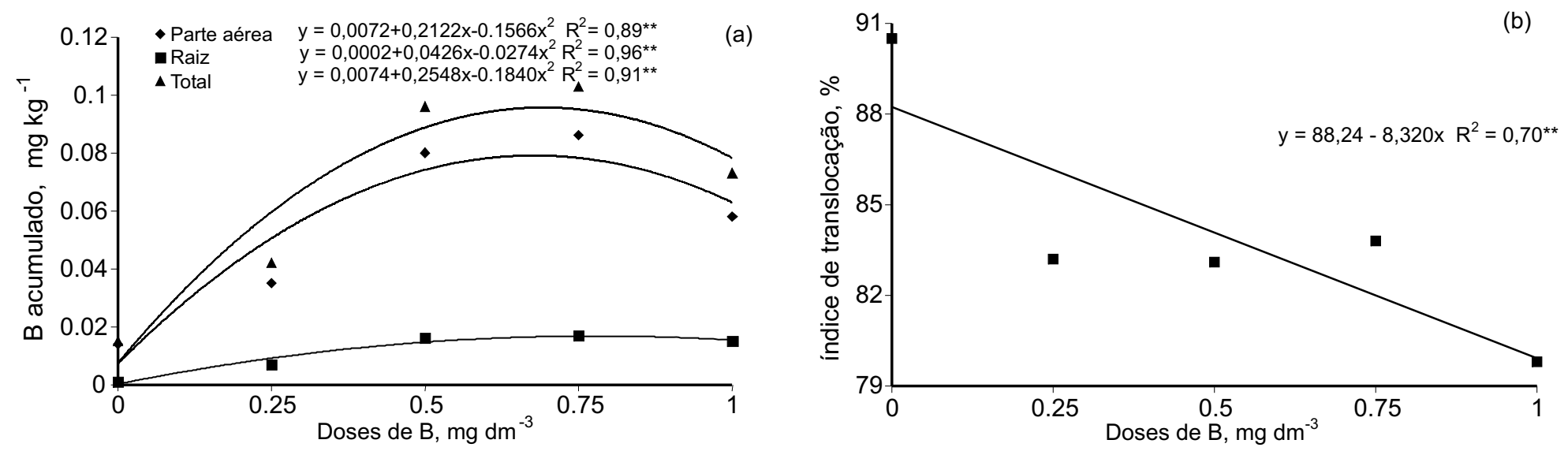

FIGURA 5 - Efeito da aplicação de boro no acúmulo de B na parte aérea, nas raízes e total (parte aérea+raiz) das plantas (a) e no índice de translocação de B (b) de mudas de maracujazeiro-amarelo, cultivadas em substrato do Latossolo Vermelho distrófico, 70 dias após a semeadura.

em razão da aplicação de níveis altos de B. A ausência de efeitos significativos do B nos teores de K está de acordo com Yamagishi \& Yamamoto (1994) e em desacordo com Power \& Woods (1997), que observaram redução do teor de $\mathrm{K}$ nas plantas com aumento da aplicação de B.

As maiores doses de B não provocaram, no final do período experimental, os sintomas característicos de toxidez, o que pode ser explicado pelo teor de $\mathrm{B}\left(33-36 \mathrm{mg} \mathrm{kg}^{-1}\right)$ na matéria seca das mudas (Tabelas 1 e 2), considerado ainda tolerável pelas plantas, pois encontra-se próximo da faixa adequada (40-50 $\mathrm{m} \mathrm{kg}^{-1}$ ) (Malavolta et al., 1997). Sendo que a toxicidade de B nas plantas, em geral, ocorre quando o teor fica entre 98-257 $\mathrm{mg} \mathrm{kg}^{-1}$ (Gupta, 1979).

É oportuno ressaltar que a produção de matéria seca com a aplicação de boro é explicada pela relação quadrática do teor de B da parte aérea e a matéria seca da parte aérea (MSPA) (MSPA= - 3,25+ $\left.0,653 \mathrm{~B}_{\text {(parte aérea) }}-0.0152 \mathrm{~B}_{\text {(parte aérea) }}^{2}, \mathrm{R}^{2}=0,99 * *\right)$ e o teor de $\mathrm{B}$ das raízes, e a matéria seca das raízes (MSR) das mudas (MSR $=-0,20+0,073$ $\left.\mathrm{B}_{\text {(raiz) }}-0,0016 \mathrm{~B}_{(\text {raiz) }}^{2}, \mathrm{R}^{2}=0,98 * *\right)$. Assim, a maior produção de matéria seca da parte aérea e de raiz esteve associada ao teor próximo de 22 e $24 \mathrm{mg}$ de B kg${ }^{-1}$, respectivamente. Na literatura, o teor adequado de B foliar ( $4^{\text {a }}$ folha recém-madura) em maracujazeiro adulto situa-se na faixa de 40-50 $\mathrm{mg} \mathrm{kg}^{-1}$ (Malavolta, 1989) ou de 40-60 $\mathrm{mg} \mathrm{kg}^{-1}$ (Menzel et al., 1993). Essa diferença pode ser explicada pela idade da planta e dos tecidos analisados (toda a parte aérea neste trabalho). Segundo Sotiropoulos et al. (1999), a folha é o tecido das plantas que mais acumula o boro, especialmente nas margens.

O aumento do teor de B na planta foi constatado também na parte aérea como na raiz. O maior acúmulo de $\mathrm{B}$ na planta correspondeu à dose próxima de $0,75 \mathrm{mg} \mathrm{dm}^{-3}$ (Figura $5 \mathrm{a}$ ); dose esta que promoveu um teor de $25 \mathrm{mg} \mathrm{kg}^{-1}$ (Tabela 1); resposta coincidente à encontrada por Vasconcellos et al. (2001) em folhas de maracujazeiro. Salienta-se que $80-91 \%$ do boro acumulado pela planta se concentrou na parte aérea das mudas. Resultado semelhante foi obtido por Zhao Duli \& Derrick (2002), indicando alto acúmulo de B na parte aérea e baixo nas raízes, e a maior parte do $\mathrm{B}$ acumulado na parte aérea das plantas encontra-se nas folhas (70-80\%).

Salienta-se ainda que, com o aumento das doses de B, houve redução do índice de translocação do $\mathrm{B}$, ou seja, houve maior acumulação de $\mathrm{B}$ nas raízes (no interior das células ou no espaço livre aparente) em detrimento da parte aérea (Figura 5b). Assim, as plantas deficientes em B apresentaram maior habilidade no transporte do B das raízes para a parte aérea. Esta maior mobilização do $B$ para a parte aérea das plantas-testemunha (sem B) pode ter recebido contribuição do Ca vindo da calagem prévia do substrato $\left(\mathrm{Ca}=27 \mathrm{mmol}_{\mathrm{c}} \mathrm{dm}^{-3}\right)$. Carpena et al. (2000) verificaram que a contribuição do Ca na maior mobilidade do B ocorreu apenas nas plantas com baixo teor de B, enquanto, nas plantas com teor de B adequado, não houve efeito do $\mathrm{Ca}$.

\section{CONCLUSÕES}

1) As mudas de maracujazeiro responderam à aplicação de boro em substrato com baixa concentração de $\mathrm{B}\left(0,06 \mathrm{mg} \mathrm{dm}^{-3}\right)$.

2) $\mathrm{O}$ maior desenvolvimento das plantas esteve associado à dose próxima de $0,5 \mathrm{mg} \mathrm{de} \mathrm{B} \mathrm{dm} \mathrm{d}^{-3} \mathrm{e}$ à concentração de $0,4 \mathrm{mg}$ de $\mathrm{B} \mathrm{dm}-$ ${ }^{3}$ no substrato e um teor de $22 \mathrm{mg}$ de $\mathrm{B} \mathrm{kg}^{-1}$ na parte aérea.

\section{REFERÊNCIAS}

BATAGLIA, O.C.; RAIJ, B.van. Eficiência de extratores de micronutrientes na análise do solo. Revista Brasileira de Ciência do Solo, Campinas, v.14, p.25-31, 1990.

BATAGLIA, O.C.; FURLANI, A.M.C.; TEIXEIRA, J.P.F.; FURLANI, P.R.; GALLO, J.R. Métodos de análise química de plantas. 
Campinas: Instituto Agronômico de Campinas, 1983. 48p. (Boletim Técnico, 78).

BUZETTI, S.; MURAOKA, T.; SÁ, M.E. Doses de boro na soja, em diferentes condições de acidez do solo: I. Produção de matéria seca e de grão e nível crítico no solo. Revista Brasileira Ciência do Solo, Campinas, v.14, p57-161,1990a.

BUZETTI, S.; MURAOKA, T. ; SÁ, M.E. Doses de boro na soja, em diferentes condições de acidez do solo: II. Níveis críticos nas plantas e nos grãos. Revista Brasileira Ciência do Solo, Campinas, v.14,p.163-166,1990b.

CARPENA, R.O.; ESTEBAN, E.; SARRO, M.J.; PENÃLOSA, J.; GÁRATE, A.; LUCENA, J.J.; ZORNOZA, P. Boron and calcium distribution in nitrogen-fixing pea plants. Plant Science, Linerick, v.151, p.163-170, 2000

GRASSI FILHO, H.; AMANO, F.Y.I.; SANTOS, C.H.; CAMPOS, A.J.; MARTINS, N.G.S. Níveis de boro no desenvolvimento de mudas de maracujazeiro doce (Passiflora alata, Dryand), em solução nutritiva. In: REUNIÃO BRASILEIRA DE FERTILIDADE DO SOLO E NUTRIÇÃO DE PLANTAS, 24., 2000, Santa Maria. Resumos expandidos... Viçosa: Sociedade Brasileira de Ciência do Solo, 2000. CD-ROM.

GUPTA, U.C Factors affecting boron uptake by plants. Boron and Its Role. In: GUPTA, U.C. (Ed.). Boron and its role in crop production. Boca Raton: CRP Press, 1993a. p.87-123.

GUPTA, U.C. Boron and its role in crop production. Boca Raton: CRC Press, 1993b. 237p.

GUPTA, U.C. Boron nutrition of crops. Advances in Agronomy, San Diego, v.31, p.373-377, 1979.

KIRK, G.J.; LONERAGAN, J.F. Functional boron requirement for leaf expansion and its use as a critical value for diagnosis of boron de eficiency in soybean. Agronomy Journal,, Madison, v.80,p.758762,1988

MACHADO, R.A.F. Fósforo e zinco na nutrição e crescimento de mudas de maracujazeiro-amarelo (Passiflora edulis f. flavicarpa Deg.). 1998. 93 f. Dissertação (Mestrado) - Universidade Federal de Lavras, Lavras, 1998.

MAGALHÃES, J.R.; MONNERAT, P.H. Aplicação foliar de boro na prevenção de deficiência e na composição mineral do tomateiro. Pesquisa Agropecuária Brasileira, Brasília, v.13,p.81-89,1978.

MALAVOLTA, E. ABC da adubação. São Paulo: Agronômica Ceres, 1989.292p.

MALAVOLTA, E. Manual de química agrícola: adubos e adubação. 3.ed. São Paulo: Agronômica Ceres, 1981. 594p.

MALAVOLTA, E.; VITTI, G.C.; OLIVEIRA, S.A. Avaliação do estado nutricional das plantas: princípios e aplicações. Piracicaba: POTAFÓS, 1997.319p.

MARSCHNER, H. Mineral nutrition of higher plants. $2^{\text {nd }}$ ed. San Diego: Academic, 1995. 902p.

MENZEL, C.M.; HAYDON, G.F.; DOOGAN, V.J.; SIMPSON, D.R. New standard leaf nutrient concentrations for passion fruit based on sasonal phenology and leaf composition. Journal Horticultural Science, Ashford, v.68, p.215-229,1993.

MINAMI, K.; TESSARIOLINETO, J.; PENTEADO, S.R.: ESCARPARI FILHO, J.A. Produção de mudas hortícolas de alta qualidade. Piracicaba: ESALQ/SEBRAE, 1994. 155p.

MORALES ABANTO, A.; MÜLLER, L.E. Alteraciones producidas en el maracuja (Passiflora edulis $f$. flavicarpa) por deficiencias de manganeso, hierro, boro, y zinc. Turrialba, Coronado, v.27,p.163168,1977
OLIVEIRA JR., J.P.; FONSECA, E.B.A.; MAGALHÃES, R.T.; LEANDRO, W.M. Efeito da omissão de B, Cu, Mo e Zn no substrato para formação de mudas de maracujazeiro amarelo (Passiflora edulis f. flavicarpa Deneger). In: REUNIÃO BRASILEIRA DE FERTILIDADE DO SOLO E NUTRIÇÃO DE PLANTAS, 21., 1994. Petrolina. Anais... Viçosa: Sociedade Brasileira de Ciência do Solo,1994. p.426-427.

PEIXOTO, J.R.; CARVALHO, M.L.M. Efeito da uréia, do sulfato de zinco e do ácido bórico na formação de mudas do maracujazeiro amarelo. Pesquisa Agropecuária Brasileira, Brasília, v.31,p.325330,1996.

PIZA JÚNIOR, C.T.; GUAGGIO, J.A.; SILVA, J.R.; KAVATI, R.; MELETTI, L.M.M.; SÃO JOSÉ, A.R. Adubação do maracujá. In: RAIJ, B.van.; CANTARELLA, H.; GUAGGIO, J.A.; FURLANI, A.M.C. Recomendações de calagem e adubação para o Estado de São Paulo. Campinas: Instituto Agronômico de Campinas, 1996. p.148-149.

POWER, P.P.; WOODS, W.G. The chemistry of boron and its speciation in plants. In: DELL, B.; ROWN, P.H.; BELL, R.W. (Ed.). Boron in soil and plants. Plant Soil, Netherlands, v.193, p.1-13, 1997.

RAIJ, B.van.; ANDRADE, J.C.; CANTARELLA, H.; QUAGGIO, J.A. (Ed.). Análise química para avaliação da fertilidade do solo. Campinas: Instituto Agronômico de Campinas, 2001. 285p.

RAIJ, B.van; CANTARELLA, H.; QUAGGIO, J.A.; FURLANI, A.M.C. eds. Recomendações de adubação e calagem para o Estado de São Paulo. 2.ed. Campinas: Instituto Agronômico de Campinas, 1996. p.39. (Boletim Técnico, 100).

RAMON, A.M.; CARPENA-RUIZ, R.O.; GARATE, A.; BEUSICHEN, M.L-van. The effects of short term deficiency of boron on potassium, calcium and magnesium distribution in leaves and roots of tomato (Lycopersicon esculentum) plants. Developments in Plant and Soil Sciences, Dordrecht, v.21, p.87-90, 1990.

SILVA, N.M.; CARVALHO, L.H.; CHIAVEGATO, E.J.; KONDO, J.I.; BATAGLIA, O.C.; HIROCE, R.; BORTOLETTO, N.; SABINO, J.C. Estudo regional da adubação boratada do algodoeiro no estado de São Paulo. Bragantia, Campinas, v.50, p.341-358,1991.

SOTIROPOULOS, T.E.; THERIOS, I.N.; DIMASSI, K.N. Calcium application as a means to improve tolerance of kiwifruit (Actinidia deliciosa L.) to boron toxicity. Scientia Horticulturae, Amsterdan, v.81, p.443-449,1999.

VASCONCELLOS, M.A.S.; BRANDÃOFILHO, J.U.T. \& VIEITES, R.L. Maracujá-doce.. In: C.H. Bruckner; Picanço, M.C.(Ed.). Maracujá: tecnologia de produção, pós-colheita, agroindústria, mercado. 20 ed. Porto Alegre: Editora Cinco Continentes, 2001. p.387-416

YAMADA, T. Boro: será que estamos aplicando a dose suficiente para o adequado desenvolvimento das plantas? Informações Agronômicas, Piracicaba, v.90, p.1-5, 2000.

YAMAGISHI, M; YAMAMOTO, Y. Effects of boron on nodule development and symbiotic nitrogen fixation in soybean plants. Soil Science and Plant Nutrition, Bunkyo-Ku, v.40, p.265-274, 1994.

ZHAO DULI; DERRICK M. Cotton carbon exchange, nonstructural carbohydrates, and boron distribution in tissues during development of boron deficiency. Field Crops Research, Amsterdan, v.78, p.75-87, 2002. 